\title{
PERANAN GURU PPKN DALAM MENUMBUHKAN SIKAP NASIONALISME DAN PEMBENTUKAN KARAKTER PESERTA DIDIK DI SMK GANESA SATRIA 2 DEPOK
}

\author{
Iis Dewi Lestari \\ Program Studi Informatika, FTIK, Universitas Indraprasta PGRI \\ Email : Iisdewi_lestari@yahoo.co.id \\ Diterima: 23 Oktober 2019; Direvisi: 13 Maret 2020; dipublikasikan: 30 April 2020
}

\begin{abstract}
Nasionalism is a transcendent value of Pancasila and students must have fill independence as a next generation to give the contributions for our country. So it can come true of students character can competitives and tough in the middle of globalization. The purpose of this study is to find the PPKN teacher for developing the nasionalism character of students in SMK Ganesa Satria 2 Depok. Methodology research is descriptive. Technique data collection was carried out by interviews, observations and documentation. Technique data analysis in this research using reduction data, presentation of data, and withdrawal of conclusion. The results of this research are 1) PPKn teacher in SMK Ganesa Satria 2 Depok have very large role in developing an attitude of nationalism and the formation of the students character are implement through subjects PPKn, 2)through PPKn training teacher, the organization of OSIS in this school can growing the nationalism attitude and form students character appropiate transcendet value of Pancasila, 3)Growing attitude of nationalism student character not only job for the PPKn teacher but its job for the other teacher in the school and specially for their parents, 4) PPKn teacher have high quality to growing the nasionalism students character at SMK Ganesa Satria 2 Depok, its can show from his job performance as a teacher have good quality and his profesionalism as a teacher did obligations and excercise right will be models for the students in formation of students character.
\end{abstract}

Key Words: PPKn teacher, Nasionalism, Character

\begin{abstract}
ABSTRAK
Nasionalisme merupakan nilai luhur Pancasila yang perlu dimiliki peserta didik sebagai generasi penerus bangsa untuk mengisi kemerdekaan dan mampu memberikan kontribusi bagi negara sehingga dapat terwujud karakter peserta didik yang dapat berdaya saing dan tangguh di tengah era globalisasi. Tujuan dari penelitian ini adalah untuk mengetahui peran guru PPKn dalam menumbuhkan sikap nasionalisme dan pembentukan karakter peserta didik di SMK Ganesa Satria 2 Depok. Metodologi penelitian ini adalah deskriptif. Teknik pengumpulan data dilakukan dengan wawancara, pengamatan dan dokumentasi. Teknik analisis data dalam penelitian ini dengan menggunakan reduksi data, penyajian data, dan penarikan kesimpulan. Hasil penelitian ini adalah 1) Guru PPKn di SMK Ganesa Satria 2 Depok memiliki peran yang sangat besar dalam menumbuhkan sikap nasionalisme dan pembentukan karakter peserta didik yang diterapkan melalui mata pelajaran PPKn, 2) Melalui Pembinaan Guru PPKn, Kegiatan OSIS dapat langsung diterapkan untuk menumbuhkan sikap nasionalisme yang dapat diimplementasikan dan membentuk karakter peserta didik sesuai nilai luhur Pancasila, 3) Dalam menumbuhkan sikap nasionalisme tidak hanya menjadi tugas dari Guru PPKn namun menjadi tugas semua guru dan terlebih orang tua murid, 4) Guru PPKn di SMK Ganesa Satria 2 memiliki kualitas dan prefosionalisme yang tinggi dalam menjalankan hak dan kewajibannya sebagai guru di sekolah sehingga dapat dijadikan teladan oleh peserta didik dalam pembentukan karakter.
\end{abstract}

Kata Kunci : Guru PPKn, Nasionalisme, Karakter 


\section{PENDAHULUAN}

Dalam Undang-Undang No. 20 tahun 2003 tentang Sistem Pendidikan Nasional BAB 2 Pasal 3 dinyatakan bahwa pendidikan nasional berfungsi mengembangkan kemampuan dan membentuk watak serta peradaban bangsa yang bermartabat dalam rangka mencerdaskan kehidupan bangsa, bertujuan untuk berkembangnya potensi peserta didik agar menjadi manusia yang beriman dan bertakwa kepada Tuhan Yang Maha Esa, berakhlak mulia, sehat, berilmu, cakap, kreatif, mandiri, dan menjadi warga negara yang demokratis serta bertanggung jawab. Daoud Joesoef pada harian Kompas 3 September 2008 menyatakan bahwa pendidikan pada hakikatnya adalah suatu proses sedini mungkin kepada peserta didik untuk diberikan pemahaman, keterampilan yang sesuai dengan aturan yang berlaku di masyarakat sehingga dapat berguna bagi bangsa dan negara.

Empat pilar pendidikan yang dapat dijadikan sebagai pondasi dalam pendidikan karakter yaitu belajar mengetahui, belajar berbuat, belajar menjadi diri sendiri dan belajar hidup bersama. Keempat pilar ini yang berasal dari UNESCO dapat diadopsi oleh para guru dalam rangka memberikan penanaman nilai karakter dalam proses pembelajaran di kelas ( Hadi Wiyono, 2012: 5). Jika guru gagal dalam dalam menjaga komunikasi dengan orang tua murid tentang kemajuan perkembangan anak di sekolah maka guru akan kehilangan kesempatan untuk membuat jembatan komunikasi yang sangat penting dalam pembentukan karakter peserta didik. Mulyasa menjelaskan beberapa cara dalam membangun karakter peserta didik oleh guru antara lain dengan membuat formulir dan catatan yang mencakup (Mulyasa, 2014: 162): 1). Pemberian tugas yang belum selesai, 2). Catatan tentang perbuatan yang dilakukan anak di sekolah, 3). Buku catatan setiap berkomunikasi dengan guru, 4). Surat untuk meminta orang tua datang ke sekolah

Crow dalam Djaali menyatakan bahwa karakter adalah hasil kegiatan yang sangat mendalam dan kekal yang nantinya akan membawa ke arah pertumbuhan sosial. Perkembangan sosial disini dapat diartikan kegiatan yang terarah dari individu dalam pemahaman atas warisan sosial yang dirangsang oleh adat istiadat, lingkungan sosial, kebiasaan dan minat kelompok (Djaali, 2009: 48). Pendidikan pada usia remaja khususnya dalam pembentukan karakter peserta didik dapat dipengaruhi oleh peran pendidik yang dapat mengontrol kegiatan peserta didik yang dapat memberikan kesempatan kepada peserta didik untuk berpartisipasi dalam kegiatan sosial (Djaali, 2009: 59).

Taufik Abdullah seorang sejarawan menyatakan bahwa nasionalisme merupakan rasa cinta terhadap tanah air dan bangsa yang menjadi penggerak pemersatu masyarakat dalam mewujudkan cita-cita bangsa Indonesia, (Taufik, 2007: 33). Cendikiawan Soedjatmoko menyatakan bahwa nasionalisme harus diiringi oleh sebuah pengetahuan, pemahaman, pengertian, kebijaksanaan secara sadar akan sejarah yang terjadi di suatu bangsa (Soedjatmoko, 1991: 30). Latar belakang lahirnya nasionalisme di Indonesia adalah rasa senasib sepenanggungan yang dialami oleh masyarakat Indonesia dari penjajahan. Nasionalisme merujuk pada adanya persamaan nilai-nilai dasar untuk kepentingan bersama.

Martianah dalam Anggraeni dan Faturochman menjelaskan beberapa ciri sikap nasionalisme modern antara lain 1) mencintai tanah air dan bangsa dan mengutamakan kepentingan bersama, 2) berpartisipasi dalam pembangunan, 3) menegakkan hukum dan keadilan sosial, 4) memanfaatkan iptek dan berorinetasi ke masa depan, 5) berprestasi, mandiri dan menghargai orang lain, 6) siap bersaing dengan bangsa lain (Anggraeni dan Faturochman, 2004: 71).

Nasionalisme yang diserap ke dalam bahasa Indonesia mengandung arti paham untuk mencintai bangsa dan kesadaran keanggotaan suatu bangsa secara bersama-sama untuk mencapai, mempertahankan dan mengabadikan integritas bangsanya, (Yatim , 2001: 684). Nasionalisme di 


\section{Sosio e-kons}

Volume 12, No. 1, April 2020, pp. 44-49

e-ISSN: 2502-5449

p-ISSN: 2085-2266

DOI : 10.30998/sosioekons.v12i1.5071

Indonesia adalah tidak membeda-bedakan warga negara karena golongan tertentu, dengan keanekaragaman yang dimiliki Indonesia tetap dapat diakui dan dihargai, (Maksum dan Affan, 2016: 68). Dari beberapa pengertian diatas maka dapat diketahui bahwa nasionalisme adalah semangat kebangsaan dengan orientasi kepentingan bersama ditengah keanekaragaman masyarakat yang dapat dicerminkan melalui cinta tanah air, berpartisipasi dalam pembangunan, menegakkan hukum dan keadilan, berprestasi, mandiri, bertanggungjawab dan menghargai orang lain serta dapat bersaing baik nasional maupun internasional. Nasionalisme merupakan nilai luhur Pancasila yang perlu dimiliki peserta didik sebagai generasi penerus bangsa untuk mengisi kemerdekaan dan mampu memberikan kontribusi bagi negara melalui perwujudan dari nilai-nilai nasionalisme sehingga dapat terwujud karakter peserta didik yang dapat berdaya saing dan tangguh.

\section{METODE}

Metode penelitian ini adalah menggunakan penelitian kualitatif dengan pendekatan deskriptif yaitu menggambarkan peristiwa yang terjadi di lokasi penelitian. Jumlah sampel yang digunakan adalah 1 guru PPKn yang dijadikan sebagai objek penelitian. Adapun langkah-langkah yang dilakukan dengan teknik pengumpulan data yaitu 1) melakukan observasi kepada peserta didik di kelas X, XI dan XII untuk melihat perilaku peserta didik di lingkungan sekolah ,2) wawancara kepada Guru PPKn sebagai objek penelitian dan melakukan wawancara kepada Kepala Sekolah dan Wakil Kurikulum sebagai tambahan untuk mendapatkan informasi sebagai informan yang mendukung terkait objek penelitian dan 3) melakukan dokumentasi terkait data-data yang relevan dengan hasil penelitian. Lokasi penelitian di SMK Ganesa Satria 2 Depok, Jl. Merdeka Raya Depok dengan waktu penelitian Maret-Juni 2019. Teknik analisis data dalam penelitian ini adalah reduksi data, penyajian data, dan kesimpulan.

\section{HASIL DAN PEMBAHASAN}

\section{HASIL}

\section{Deskripsi Objek Penelitian}

SMK Ganesa Satria 2 berada di Jalan Merdeka Raya Komplek Yayasan Depok 2 Timur dengan akreditasi A. SMK Ganesa Satria 2 memiliki dua kejuruan yaitu Teknik Kendaraan Ringan dan Teknik Sepeda Motor dengan jumlah peserta didik 125 dari kelas X sampai dengan kelas XII. Peserta didik dengan jenis kelamin laki-laki sebanyak 120 dari total 125 peserta didik. Jumlah guru dan staf sebanyak 20 orang. Guru mata pelajaran PPKn bernama Bapak Ayuda Suryasandhi, S.Pd. merupakan guru tetap yayasan yang sudah 7 tahun mengajar. Kepala sekolah Bapak M.Husni, S.Pd.

\section{Observasi}

Observasi yang dilakukan antara lain mengamati beberapa kegiatan :

1. Kegiatan belajar mengajar PPKn di dalam kelas

Dari hasil observasi dapat diketahui bahwa pembelajaran di kelas X Teknik Kendaraan Ringan cukup interaktif karena wibawa guru dan materi yang disampaikan oleh Bapak Ayuda selaku guru PPKn diterima baik oleh peserta didik dengan diawali datang tepat waktu dan memiliki kualitas belajar guru yang profesional. Dengan metode penggunaan audiovisual 
menayangkan film, diskusi secara demokratis memberikan semangat belajar yang baik kepada peserta didik.

\section{Kegiatan OSIS}

Dalam kegiatan di OSIS banyak mengandung nilai-nilai positif bagi peserta didik, khususnya dalam menumbuhkan sikap nasionalisme yang dapat mengantarkan peserta didik membentuk karakter yang baik. Hal ini dilihat dari program-program dan struktur organisasi OSIS yang terdapat di SMK Ganesa Satria 2 dimana terdapat seksi 2 kepribadian unggul, wawasan kebangsaan dan bela negara.

\section{Wawancara}

Berdasarkan hasil wawancara dengan guruPPKn di SMK Ganesa Satria 2 Depok yaitu Bapak Ayuda Suryasandhi, menurut beliau guru PPKn tidak hanya dituntut untuk mampu memaknai pembelajaran tetapi yang paling penting adalah bagaimana menjadikan pembelajaran PPKn sebagai ajang pembentukan karakter dan perbaikan kualitas diri peserta didik. Adapun cara-cara yang dilakukan oleh Bapak Ayuda sebagai guru PPKn dalam menumbuhkan semangat nasionalisme dan pembentukan karakter peserta didik antara lain:

1. Melalui mata pelajaran PKn diwajibkan kepada seluruh peserta didik untuk mencapai nilai KKM 75. Selain itu tidak hanya secara kognitif, melalui mata pelajaran PKn, peserta didik dituntut untuk jujur, toleransi, bekerja sama, mencintai tanah air Indonesia. Bapak Ayuda pada saat kegiatan pembelajaran PPKn memberikan tontonan yang dapat menumbuhkan semangat nasionalisme generasi muda seperti peristiwa perumusan Pancasila, G 30 SPKI, reformasi. Melalui film yang ditayangkan dikelas, peserta didik menjadi lebih tertarik dalam menumbuhkan semangat nasionalisme dan dapat membentuk peserta didik sebagai generasi muda yang mandiri dan bertanggungjawab serta cinta tanah air.

2. Dengan kedisiplinan yang dilakukan oleh Bapak Ayuda memiliki peran penting bagi peserta didik sebagai teladan. Bapak Ayuda merupakan sosok guru yang profesional, berkualitas, disiplin dan dekat dengan peserta didik.

\section{PEMBAHASAN}

Berdasarkan dari hasil observasi dan wawancara yang dilakukan kepada Guru PKn Bapak Ayuda dan Peserta didik di SMK Ganesa Satria 2 Depok dapat diketahui bahwa nasionalisme merupakan semangat kebangsaan yang perlu ditumbuhkan kepada generasi muda yang dapat membentuk karakter peserta didik menjadi sosok individu yang saling menghargai, mengetahui perjalanan bangsa Indonesia, bertanggungjawab, mandiri serta disiplin sesuai dengan nilai luhur Pancasila. Dengan semangat nasionalisme yang tinggi tentunya akan mencetak generasi muda yang memiliki karakter yang unggul, positif dan dapat berdaya saing.

Guru PPKn Bapak Ayuda memiliki peran yang besar dalam menumbuhkan semangat nasionalisme kepada peserta didik. Hal ini karena melalui mata pelajaran PPKn, bapak Ayuda dapat memberikan pengetahuan, pemahaman tentang nasionalisme yang dikaitkan dengan materi ajar PPKn di SMK Ganesa Satria. Namun menurut beliau bahwa saat ini muatan materi yang terdapat dalam mata pelajaran PPKn lebih membahas permasalahan kewarganegaraan, demokrasi, hukum, ham. Yang menjadi pusat perhatian Bapak Ayuda adalah sebaiknya muatan PPKn kepada peserta didik lebih banyak juga mempelajari tentang moral dan akhlak karena melihat saat ini peserta didik 
sangat butuh pembinaan tentang bagaimana tata krama, sopan santun serta nilai-nilai moral yang perlu ditanamkan.

Berdasarkan hasil penelitian (Abdullah Jainudin, 2015: 464) dikatakan bahwa peran guru dalam internalisasi nilai-nilai positif peserta didik tidak dapat digantikan oleh apapun. Oleh karena itu, sikap dan contoh positif dari seorang guru dapat mengembalikan jati diri peserta didik dalam pembentukan karakter. Disisi lain, penanaman sikap nasionalisme ini tidak mutlak menjadi tugas guru PPKn namun semua guru terlebih lagi orang tua. Karena guru PPKn hanya bertatap muka 2 jam dalam satu minggu sehingga sulit rasanya jika hanya dibebankan kepada Guru PPKn saja. Sehingga bantuan dan kerjasama orang tua perlu ditingkatkan agar peserta didik memiliki semangat nasionalisme yang tinggi sehingga dapat menghasilkan karakter peserta didik yang mandiri, tangguh dan dapat bersaing.

Hal ini senada disampaikan oleh I Made Kartika dalam Jurnal Kajian Widya Accarya dalam hasil penelitiannya dikatakan bahwa guru PPKn memiliki pengaruh yang besar dalam memberikan teladan yang positif bagi peserta didik di lingkungan sekolah. Jika guru PPKn dapat memberikan contoh kedisiplinan, partisipasi positif di lingkungan sekolah tentunya peserta didik akan menyontoh dan meneladani dalam pembinaan yang dilakukan guru PPKn kepada peserta didik untuk menumbuhkan sikap nasionalisme. Nasionalisme adalah gerakan ideologis untuk mencapai dan mempertahankan otonomi, kesatuan dan identitas yang sejumlah anggotanya bertekad membentuk suatu bangsa yang potensial (Smith, 2012: 11).

\section{SIMPULAN}

1. Guru PPKn di SMK Ganesa Satria 2 Depok yaitu Bapak Ayuda memiliki peran yang sangat besar dalam menumbuhkan sikap nasionalisme dan pembentukan karakter peserta didik. Hal ini dapat diketahui pada saat pembelajaran PPKn, bapak Ayuda berusaha semaksimal mungkin membangun sikap nasionalisme dalam pembelajaran melalui berdoa sebelum belajar, menyanyikan lagu wajib nasional untuk kegiatan penutup pembalajaran, pemberian tugas-tugas individu atau kelompok untuk menumbuhkan semangat belajar, toleransi dan kerjasama dalam mengerjakan tugas, pemberian tugas diskusi untuk sarana demokrasi di dalam kelas, penggunaan media audiovidual atau film dalam pembelajaran PPKn.

2. Bapak Ayuda selaku Guru PPKn juga aktif dalam pembinaan OSIS yang dapat menumbuhkan sikap nasionalisme dan pembentukan karakter peserta didik. Sebagai pembina OSIS melalui seksi 2 bidang kepribadian unggul, wawasan kebangsaan dan bela negara tentunya peserta didik dituntut untuk memahami dan melaksanakan program-program kegiatan OSIS yang dapat menumbuhkan sikap nasionalisme dan membentuk karakter peserta didik yang aktif dalam kegiatan positif. Hal ini didukung dan dibina oleh Bapak Ayuda selaku Guru PPKn.

3. Dalam menumbuhkan sikap nasionalisme tidak hanya menjadi tugas dari Guru PPKn namun menjadi tugas semua guru dan terlebih orang tua murid. Dengan metode pembiasaan yang dapat diteladani melalui guru PPKn di sekolah tentunya pembentukan karakter peserta didik juga besar dipengaruhi oleh lingkungan keluarga.

4. Sebagai guru PPKn, bapak Ayuda memiliki kualitas dan prefosionalisme yang tinggi dalam menjalankan hak dan kewajibannya sebagai guru di sekolahsehingga peserta didik dapat meneladaninya. 


\section{Sosio e-kons}

Volume 12, No. 1, April 2020, pp. 44-49

e-ISSN: 2502-5449

p-ISSN: 2085-2266

DOI : 10.30998/sosioekons.v12i1.5071

\section{SARAN}

Adapun selain guru PPKn berperan sangat besar di sekolah dalam menumbuhkan sikap nasionalisme dan pembentukan karakter peserta didik sebaiknya peran kepala sekolah dan guru Bimbingan Konseling dapat bersinergi dengan guru PPKn untuk mewujudkan peserta didik yang memiliki karakter sesuai dengan nilai-nilai Pancasila. Selain itu, orang tua juga menjadi kunci utama dalam menghasilkan anak-anaknya memiliki karakter dan sikap nasionalisme yang dapat diimplementasikan di sekolah maupun di lingkungan keluarga. Serta pihak sekolah sebaiknya selalu memberikan dukungan kepada peserta didik dan guru untuk memfasilitasi segala kegiatan yang berkaitan dengan hal yang positif sehingga dapat menumbuhkan semangat dalam diri guru dan peserta didik untuk terus melakukan kegiatan positif dalam menumbuhkan sikap nasionalisme dan menghasilkan karakter peserta didik yang sesuai Pancasila.

\section{DAFTAR RUJUKAN}

Abdullah, Jainudin. Peran Guru dalam Menumbuhkan Sikap Nasionalisme pada Siswa SMP Negeri 1 Babang Kec. Bacan Timur. Edukasi Jurnal Pendidikan Vol.13 No.2, 2015, hal 462-466.

Abdullah, Taufik. (2007). Harian Kompas 18 Agustus 2007, hal 33.

Djaali. (2009). Psikologi Pendidikan. Jakarta: Bumi Aksara

Faturochman, Anggraeni Kusumawardani.( 2004). Nasionalisme dalam Jurnal Buletin Psikologi. Tahun XII No. 2 Desember. ISSN 0854-7108.

Hadi Wiyono. (2012). Pendidikan Karakter Dalam Bingkai Pembelajaran di Sekolah. Jurnal Ilmiah Civics. Vol. II No. 2 Juli

Joesoef, Daoud. Esensi Pendidikan .Harian Kompas 3 September, 2008.

Kartika, I. Made. (2016). Peranan Guru PPKN dalam Mengembangkan Karakter Dan Sikap Nasionalisme Pada Siswa SMA Dwijendra Denpasar. Jurnal Kajian Pendidikan Widya Accarya FKIP: Universitas Dwijendra. ISSN No. 2085-0018. Maret Hal 16-29.

Maksum, Hafidh dan Affan, Hussin. Membangun Kembali Sikap Nasionalisme Bangsa Indonesia dalam Menangkal Budaya Asing di Era Globalisasi. Jurnal Pesona Dasar Universitas Syiah Kuala, PGSD,Vol.3 No. 4 , 2016, hal 65-72.

Mulyasa, E. (2014). Manajamen Pendidikan Karakter. Jakarta: Bumi Aksara.

Soedjatmoko. (1991). Nasionalisme Sebagai Prospek Belajar dalam Majalah Prisma.

Smith, Antony, D. (2012). Nasionalisme Teori Ideologi Sejarah. Jakarta : Erlangga

Undang-Undang N0. 20 tahun 2003 tentang Sisdiknas

Yatim, B. (2001). Soekarno, Islam dan Nasionalisme. Bandung: Nuansa. 